\title{
Blended learning in the master's program
}

\author{
D.M. Voronin ${ }^{1 *}, O . A$. Zavaltseva $^{2}$, and O.V. Khotuleva ${ }^{3}$ \\ ${ }^{1}$ University for Humanities and Technologies, Moscow region, Orekhovo-Zuevo, Russia \\ ${ }^{2}$ University for Humanities and Technologies, Moscow region, Orekhovo-Zuevo, Russia \\ ${ }^{3}$ University for Humanities and Technologies, Moscow region, Orekhovo-Zuevo, Russia
}

\begin{abstract}
The paper is devoted to the usage of a mixed learning model with elements of project activity in the master's program. Master's programs are implemented at the State University of Humanities and technology from the 2018/2019 academic year at the faculty of biology and chemistry. The main idea of implementing blended learning is to improve the quality of the educational process and the practical application of learning outcomes in teaching activities. The students involved in are this program are all practical teachers and have real opportunities to implement the results of the educational process in school practice. Within the framework of the educational program, a system has been developed to such as extend that ensures the process of creating and implementing author's projects in the educational space of the school. The undergraduates create their own projects and implement them in the school environment. The projects are the product of training, which gives the opportunity of the educational program.
\end{abstract}

\section{A problem statement}

The Moscow region is a rapidly developing region, where the population is growing significantly and a large number of secondary schools are being built. Increasing the number of students requires training a large number of personnel. According to requests from the education departments of the Moscow region, there are more than 40 new vacancies for biology teachers just in 2020. A large request is also received from metrological institutions [1].

In the context of digitalization of society, there is a demand for new technologies for training biology teachers, which are a symbiosis of the full-time system and the e-learning system. A large number of hours of the curriculum are allocated for independent work. At creates the necessity for preparing high-quality remote resources and the usage of existing digital platforms (http://human.biodigital.com/index.html; http://school-collection.edu.ru/; http://fcior.edu.ru/; http://bio.1september.ru/; http://www.sbio.info/) [2]. The formation of a system of mixed training of biology teachers in master's programs to improve the effectiveness of education is becoming urgent.

\footnotetext{
*Corresponding author: ipcs-profped@yandex.ru
} 


\subsection{The objective of the work}

Changes in the higher education system in the Russian Federation and the introduction of the digital economy represent serious challenges [3], which need to be eliminated by introducing innovative educational technologies [4]. An important problem of the modern higher education system is the personalization of educational trajectories [5]. The main factors of personalization of educational programs are: project activities, research activities, criteria-based assessment, blended learning and individual curriculum training [6].

Personalization of the learning process is understood as:

- creating an individual profile of the student;

- development of individual educational routes that take into account the abilities and interests of the student;

- consistent development of skills and competencies;

- assessment of the student's progress;

- the formation of flexible educational environment with the use of technology. The most popular tools in the world for personalizing and improving the effectiveness of education at the moment are mixed and project-based learning technologies [7].

Mixed learning systems do not have a specific authorship. Their formation occurred spontaneously, under the influence of individual attempts to change the methodology and approach to education [8].

In fact, "mixed learning" is an educational technology that combines the work of a teacher and online learning. Mixed learning involves elements of independent control of individual parameters of the educational process. Control is carried out over the vectors, time, place and pace of training, as well as interaction with the teacher [9].

Some authors gives the following definition of blended learning: "this is the range of opportunities presented by combining the Internet and electronic media, with forms that require physical presence in the classroom of the teacher and students" [10].

Coming to conclusion from these definitions, it can be argued that the technology of mixed learning is an approach that allows you to use the positive features of face-to-face and e-learning most effectively, as well as partially avoid the main disadvantages of both technologies [11].

The main advantages of face-to-face training include natural reactions from participants in the educational process, the ability to display a flexible and instant reaction of the teacher to the actions of the student [12]; emotional interaction, with the formation of direct personal connections, the ability to display emotional intelligence [13]. The main advantages of e-education are: the possibility of constant interaction between the student and the teacher [14]; increasing the degree of individualization of training; expansion the opportunities for communication; high involvement student in the learning process [15].

These training technologies have a number of negative features [2]. Internal training is clearly limited time to communicate with the teacher, lack of interactivity with the learning materials (printing) [16]; low degree of individualization of education, lack of individual educational trajectory; low possibility of communication with classmates [17]. E-learning has the following disadvantages: well-known systems of electronic resource reaction to the student's actions, some delay in the teacher's reaction to the student's actions during online interaction [18].

By combining these two technologies, you can achieve the maximum effect of the learning process, avoiding negative manifestations when using a synergistic system [19].

To implement the e-learning subsystem, certain digital resources are required, which should have features [20]: a significant amount of data placed on electronic media; a variety of forms of information presentation; the ability to create tools and services for working with educational information; the ability to interact with educational content [21]. Digital resources acquire new didactic properties: 
- variety of forms to present the educational information and multimedia;

- redundancy, multi-level, variability;

- interactivity;

- flexibility and adaptability [22].

When implementing mixed learning models, it is possible to use various types of digital educational resources and online services:

- learning management systems (LMS, Moodle, Edmodo);

- digital collections of educational objects (unified Collection of Educational Resources);

- online training courses ("Mobile E-School);

- tools for creating and publishing content and training objects (1C test constructor);

- tools for communication and feedback (Mirapolis, Viber, WhatsApp, Skype, Googleduo);

- collaboration tools (Google Docs, Word Online);

- tools for creating communities (Facebook, Professionals, Vkontakte);

- tools for planning educational activities (electronic journals, organizers).

The most common models of mixed learning at the moment are the following: the inverted class model, station rotation, laboratory rotation, flexible model, and Autonomous group.

In recent years, the theme of modernization of the educational process has been clearly heard, which involves emphasizing the use of project activity skills. The task of developing new competencies and skills that enable students to implement complex projects and initiatives is widely accepted and supported by teachers and employers. In there is a shortage of management mechanisms and tools educational system that can integrate modern project training formats into the educational process on a large scale. And also educational organizations face a shortage of specialists who can ensure the development of project technologies (mentors, tutors, etc.) [23].

After analyzing the main educational trends, we decided to create our own mixed learning project, which includes elements of project activities, as a tool for personalizing and improving the quality of training at the faculty.

\section{Materials and the results of the research}

The purpose of the research is to plan and implement master's programs "Modern technologies of biological education" in the form of blended learning.

Tasks:

1. Formation of the basic principles of the mixed learning system with the introduction of elements of project activities.

2. Creating a list of tools for teacher-student interaction.

Materials and methods of research.

The study was conducted at the faculty of biology and chemistry of The state University of Humanities and technology.

In the process of theoretical analysis of sources, we used articles published in Russian and international periodicals devoted to the problems of mixed, project and distance learning. We also used materials from international conferences devoted to the design of elearning courses for mixed learning, learning in the digital educational space, as well as motivational aspects of interaction in the online environment.

The construction of the master's degree program was carried out taking into account the Federal state educational standard of higher education in the direction of training 44.04.01 Teacher education. 
A feature of any master's program is a large number of independent, practical and research work, which is reflected in the planning of the educational process. It has a special context for a master's degree. In the biological master's program, it is particularly important to have video content, video conferences and video communication, as well as equipment that can work in this format.

The first step in building the master's degree program "Modern technologies of biological education" in the direction of 44.04.01 Pedagogical education was the formation of the curriculum and description of the main educational program.

According to the standards of the Federal state educational standard, the master's curriculum includes three blocks: Block 1 "Disciplines (modules), Block 2 "Practices, including research work", Block 3 "State final certification" and "Electives", which in turn are divided into basic and variable parts. Table 1 shows the outline of the curriculum.

The basic part of Block 1 is implemented in a mixed learning model with support for the electronic information and educational environment of the State University of Humanities and technology.

The variable part of Block 1 is represented by disciplines that reflect the profile and focus of this program. This group of disciplines provides for the use of a mixed learning system, with the implementation of project tasks and the use of electronic information and educational environment of the State University of Humanities and technology. We set certain requirements for each of the projects we create: a certain significance of the problem; focus on the result (as a result, the model, the finished product, the creative work are presented); clear definition of the stages of project implementation (strict deadlines for each stage, goals and objectives of each stage, clear results of each stage); participation of experts (third-party experts who are not related to the educational process, but are directly related to the subject of project implementation); mandatory teamwork (collective creativity, team interaction, distribution of roles, overcoming problems); clear organizational structure. In our understanding, a training project combines online and offline activities, combines content-project and organizational functions for participants, a combination of types of training, and is an active learning method. Also, in the implementation of this block of disciplines, the University laboratories, computer classes, electronic libraries, as well as the University's IT Park are widely used.

Table 1. Outline of the master's curriculum.

\begin{tabular}{|c|c|}
\hline № & Subject (module) \\
\hline \multicolumn{2}{|r|}{ Basic part } \\
\hline 1 & Modern problems of science and education \\
\hline 2 & Critical analysis and methods of solving problem situations in science \\
\hline 3 & Business foreign language \\
\hline 4 & Professional career technology \\
\hline 5 & Project activities in the educational process \\
\hline 6 & Psychological and pedagogical support of students \\
\hline \multicolumn{2}{|r|}{ Variable part } \\
\hline 7 & Development of individual educational routes in biology \\
\hline 8 & Modern methods and technologies for organizing educational activities in biology \\
\hline 9 & Extracurricular activities in biology at school \\
\hline 10 & Statistical research methods in biology \\
\hline 11 & Project activities in the educational process in biology \\
\hline 12 & Modeling in biology \\
\hline 13 & Biometrics in school \\
\hline
\end{tabular}




\begin{tabular}{|l|l|}
\hline 14 & Innovative technologies in biology teaching methods \\
\hline 15 & Methodology of scientific research in biology \\
\hline Elective part. Disciplines of choice \\
\hline 16.1 & Experimental biology research in school settings \\
\hline 16.2 & Field research and features of their organization at school \\
\hline \multicolumn{2}{|c|}{ Practical training, including research work } \\
\hline State final attestation \\
\hline Facultative \\
\hline Methodological seminar on biology \\
\hline The use of modern equipment in biology lessons \\
\hline
\end{tabular}

Creating online projects is widely used in the block of elective subjects. Online projects consist of three parts: offline activities (performing an individual part), online activities (familiarizing with materials, presenting work results, publishing the final product), and online interaction (online communication, mutual verification, reflection).

54 credits are allocated for the practice block. At each practice, undergraduates complete projects. The General defense of the practice takes place in the form of a demonstration exam that meets the requirements of World Skills. Block 3 is represented by the defense of the final qualification work: the defense of a practically applied master's thesis.

The inverted class model is the simplest form of blended learning. Students work in an online learning environment using personal electronic devices that connect to the Internet. In process they learn new material or repeat what they have learned. During the lesson, the material is fixed and worked with, which can take place in the form of project activities or interactive forms. This form of training allows you to minimize front-end work and allows you to maximize the implementation of interactive forms of work in the classroom.

Laboratory rotation is a model in which part of the classes are held in a regular classroom, and part of the classes are held in a laboratory (computer class), where students work individually in an online environment. When working in an online environment, students learn new material, consolidate what they have learned, train various skills, and work on their own projects.

To implement project-based learning, we offer our students to use certain tools.

Tools for online work:

1. Use of electronic information and educational environment of the State University of Humanities and technology. The information data management system provides great opportunities for remote work with materials. This environment contains not only the materials provided by teachers, but also provides access to information data from 5 large online libraries, allows you to distribute participants into teams, make reports on the results of each planned event, allows teachers to put links to their resources outside the information and educational environment of the University, and allows you to organize communication between students and teachers. For the study of biology, the possibility of using video lectures and video information related to laboratory work is significant.

2. With the help of Google documents and tables, we create a map of problems in projects, organize deadlines for all types of work, and use it to place project solutions and final presentations of teams. A distinctive feature of this service is the ability to work with documents in groups, use a variety of formulas, a significant Arsenal of applications for working with data. undergraduates can conduct online surveys of experts and interested parties directly in the service. The service sends notifications about new messages or comments when working with documents in a group. A unique feature is the ability to 
access information using a QR code. Another important element is the ability of the teacher to give individual tasks to undergraduates and get the results of completing tasks.

3 . We have clearly seen in practice that the use of social networks in the educational process significantly changes its quality, since for undergraduates, social networks have a number of advantages, let's name the main ones:

A) a familiar and user-friendly application interface, which in fact creates a comfortable environment for sharing information, since it is more familiar than the same Moodle;

B) social accessibility of teachers in networks, a large number of tools used;

C) full identification - in social networks, the person is mostly himself and the students, and the teacher is easier to understand what kind of person you are communicating with and what he is;

D) the ability to fully filter incoming information.

4. The use of tools with the possibility of video transmission is mandatory in the study of biology. Video files are widely used during consultations and individual work with the teacher. For example, using Skype, the teacher can conduct remote consultations and laboratory classes using microscopes. When working with drugs on trinocular microscopes, one eyepiece is used for a video camera, which outputs the image directly to the network and makes it possible to conduct classes remotely. The second of the main methods of using video communication is the teacher's control over the practical activities of undergraduates, students conducting laboratory and practical classes during practical training. The third method of use is online observation of experiments using various electronic biological tools by members of project teams and discussion of the elements of conducting during the course of conducting, which allows remote correction of emerging problems. In addition to Skype, other video communication tools are also used: Viber, WhatsApp, and others.

5. The YouTube service is also Indispensable, where it is most optimal to place video information necessary for studying academic subjects.as in the case of working with video broadcasting tools, you can use laboratory biological equipment with built-in cameras for high-quality transmission of material.

We have also developed guidelines for the formation of digital literacy of students. These recommendations help to effectively implement a blended learning system. When developing a curriculum in a distance format, much attention should be paid to the formation of the main blocks of the course. in our opinion, these should be the following blocks:

- introductory instruction on the implementation of the discipline in a remote format and working on the Moodle platform;

- glossary (terms and tools used in distance education formats);

- placement of informational, lecture, methodological and control materials on the platform, as well as links to external resources that are freely available;

- placement of materials for practical training (Youtube);

- links for practical training in online video communication.

It is most rational to place the training course on the platform that the educational organization has access to, but since the most common option is to use Moodle, we use it in our work.

The first step is to familiarize students with all the features of the educational platform, its interface, Glossary, information search capabilities, passing tests, and using links to external educational resources.

The second step is to create educational content on external resources. To do this, you will need at least a laptop with a microphone and a camera, but ideally, of course, it is a video camera, a tripod, a lapel microphone, a lighting device and a computer for video and audio processing. 
At first, in order to create a training video, you need to record it. You can use a wide variety of programs to record videos, but we want to highlight some of them:

CamStudio - "Open source" is a very simple program for recording video from the screen with audio support, supports recording in several formats.

Jing can shoot videos and take screenshots, it is possible to add text boxes, arrows or rectangles to highlight the desired moments, record audio, and send the recording results to Screencast.com, Flickr, Twitter, and other web services.

Webinaria-recording is in. avi format with the possibility of further conversion to. flv, there are hot buttons for starting/stopping recording, there is an interesting function for combining two video sources (for example, a webcam and screen recording).

Windows Media Encoder is a powerful application for capturing audio and video content with multi-channel high-quality sound, supports HD.

Using the iSpring program will allow you to record a high-quality video directly from Microsoft Power Point, with the ability to demonstrate a presentation, process and overlay video and audio tracks.

The next step is usually video processing, for which we recommend the following programs:

DaVinci Resolve is a professional video editor, focused on post-production and has a huge number of tools for adjusting the image and sound. For the free version, there are several restrictions that the average user will probably not notice.

Shotcut - an editor that will be equally good for both beginners and more experienced users, has a flexible, intuitive interface and great support for video formats, transitions, combined filters and export are also available not only in a given format, but also for a specific device.

Lightworks is a program that supports multi-camera editing and color correction.

OpenShot can work with various video formats, supports an unlimited number of tracks, and also has a good gallery of transitions, filters, and titles.

Movie Maker is a simple yet functional editing app that lets you easily combine multiple videos, edit them, and add different effects. It offers a whole set of filters, transitions, and music, as well as allows you to change the playback speed and apply a blur effect to the video.

After creating the video, you will need to upload it to the video hosting service so that your students have access to the materials.

YouTube, which is the most popular video hosting service in the world and is used by billions of visitors from all over the world every day, is the most convenient way to post videos. You can post any video on YouTube, subject to copyright and content censorship. Also worth noting is a new video hosting service - Yandex, which also hosts videos for free, but there is censorship on content and copyright. An interesting tool is Vimeo, a popular video hosting service that has the main distinguishing feature-the complete absence of advertising. Do not forget about the possibility of free video posting on Vkontakte, Odnoklassniki, Video mail, and Facebook. Also popular Russian video hosting is RuTube, which also has great opportunities for hosting training videos.

The next step in preparing for the implementation of the online part of the course is to select a tool that you will use to conduct online classes in the video conference format.

Our recommendations for choosing a tool are described below.

In Google Hangouts, up to 10 people can communicate via video call. The service also supports simultaneous voice chat and allows participants to join the conference via email or a shared link.

Cisco Webex Meetings-the company's web conferencing app, free of charge, supports up to 50 video conference participants, calls are limited to 40 minutes, however, there are no restrictions on the number of calls you can make, as a gift you get 1 GB of cloud 
storage. There is support for features such as screen sharing, video recording, surveys, voice detection, and file sharing. All meetings and recordings are fully encrypted. In practice, the registration process is very difficult.

Zoom Meetings-users can hold video conferences for up to 100 participants for free, but conferences with 3 participants or more are limited to 40 minutes. The app allows participants to join via the Internet, special apps, browser extensions, and mobile devices using the iPhone and Android apps. You can record video or audio locally and share the screen image with other conference participants.

Skype-suitable for video conferences for small groups of up to 50 people, in practice, when joining more than 15 people starts to hang up a lot.

Jitsi is a free project. It should be noted that there is theoretically an "unlimited" number of service participants, but based on practice, joining more than 35 people to a video conference causes the system to overload and it starts to hang. Screen sharing and chat are possible.

Facebook Meeting Room is a completely new tool that almost does not load the system, supports video conferencing for up to 50 people. There is a possibility to show the screen, the disadvantages are the lack of video recording in the program and the lack of chat.

Discord was once created as a free messenger with support for VoIP and video conferencing for gamers. Now this service has become much more popular, even among the business audience. The great advantage of Discord is that it is free of charge.

Also, if you have a small group, do not forget about the possibility of using WhatsApp, Viber, FreeConference.

If you have the opportunity to purchase paid solutions, the most attractive option is to use Microsoft Teams, Zoom, Skype for business, TrueConf, MyOwnConference [9, 12].

The final stage is to check the competencies received by students, which are divided into theoretical and practical. Practical skills can be tested by performing exercises in a live video conference, or by recording the skills demonstrated. Writing an essay, developing a project, and passing testing in the Moodle system are suitable for the theoretical block.you can also use software solutions.

With Kahoot, teachers can simultaneously interview all students and immediately find out their weaknesses and strengths.

Quizziz-the teacher creates a survey, students respond to it, here they can't see each other's answers, and the data obtained can be uploaded in Excel format.

Mentimeter.com - free, simple, stylish online service for creating surveys and voting in real time, you can use a ready-made example or create your own presentation-an interactive whiteboard with questions.

If students are doing a project, it will be interesting if they complete it in Padlet or Google Forms, and make a presentation using Prezi or Tilda.

\section{Conclusions}

One of the main elements of success is the digital and methodological literacy of the teacher for working in a mixed learning system and implementing project-based learning, since the effectiveness of work in this system depends very much on the level of competence of the teacher. The main tasks of the teacher in the implementation of mixed and project-based training are: organization of team work, management of team progress from stage to stage, management of communication within teams, motivation management, control of understanding the tasks of the current stage, monitoring the results of participants, conflict resolution, resource and information support, organization of General events, organization of work with experts, organization of interaction, organization of reflection. 
The digital transformation of society has significantly changed the criteria for the effectiveness of educational organizations, which has led to the need to personalize the educational process at all levels of education. Understanding the need to transform higher education in the direction of its personalization and building individual trajectories for the development of students ' competencies, we can conclude that it is necessary to introduce technologies that will effectively achieve these results. Accordingly, the introduction of elements of project activities, research activities, criteria-based assessment, mixed learning and individual curricula is an urgent modern need.

Taking up the challenge of modernity on the need to introduce personalized training in the higher education system at the faculty of biology, chemistry and ecology of the State University of Humanities and technology, the master's program "Modern technologies of biological education" has been developed and implemented since the 2018/2019 academic year in the direction of training 44.04.01 Teacher education, correspondence education. This program is implemented on the basis of a mixed type of training and the use of elements of project-based training. The full-time part of the course includes classes in laboratories, an IT Park, interactive classes, consultations with experts in the field of General education, and protection of developed projects. The electronic component of the course is implemented using the electronic information and educational environment of the State University of Humanities and technology and access to electronic libraries and databases. There is a significant increase in students ' motivation to master the program materials. Prospects for further research lie in the study of improving the level of efficiency of the program development with the introduction of innovative educational technologies.

\section{References}

1. Voronin, D.M., Saienko, V.G., Tolchieva, H.V. (2020) Digital Transformation of Pedagogical Education at the University. International Scientific Conference "Digitalization of Education: History, Trends and Prospects" (DETP 2020). Atlantis Press P, 760-766. SN 2352-5398. https://doi.org/10.2991/assehr.k.200509.135

2. Voronin, D., Egorova, G., Khotuleva, O. (2019) Expirience in the implementation of blended learning with elements of project activities in the pedagogical Master's program with the example of training teachers of biology Perspectives of science \& education, 2 (38), 155-166. doi: 10.32744/pse.2019.2.13

3. Voronin, D., Mishina, O., Zavaltseva, O. (2018) Modern educational organization effectiveness criteria as education quality evaluation and quality enhancement basis. Perspectives of science \& education, 5 (35), 18-26.

4. Heik, T. (2019) 12 of the most common types of blended learning. [Internet resource]: https://www.teachthought.com/learning/12-types-of-blended-learning. Date of request: 23.09.2020

5. Bayne, S., Evans, P., Ewins, R.,Knox, J., Lamb, J., McLeod, H., O’Shea, C., Ross, J., Sheail, P. \& Sinclair, C, (2016) Manifesto for teaching online. Digital Education at Edinburg University. Retrieved from https://onlineteachingmanifesto.wordpress.com/the-text/

6. Kintu, M.J., Zhu, C., Kagambe, E. (2017) Blended learning effectiveness: therelationship between studentcharacteristics, design features andoutcomes. Technology in Higher Education, 14:7. DOI 10.1186/s41239-017-0043-4

7. Hu, M., Arnesen, K., Barbour, M.K., Leary, H. (2019) A Newcomer's Lens: A Look at K-12 Online and Blended Learning in the Journal of Online Learning Research, 5 (2), $123-144$ 
8. Fischer, L., Hilton, J., Robinson, T.J., \& Wiley, D. A Multi-institutional Study of the Impact of Open Textbook Adoption on the Learning Outcomes of Post-secondary Students, Journal of Computing in Higher Education. https://doi.org/10.1007/s12528015-9101-x. (2015)

9. Dziuban, C., Graham, C.R., Moskal, P.D., Norberg, A., Sicilia, N., Blended learning: the new normal andemerging technologies. Dziubanet al. International Journal of Educational Technology in Higher Education, 15:3, DOI 10.1186/s41239-017-0087-5. (2018)

10. Bicen, H., Ozdamli, F., Uzunboylu, H. (2014). Online and blended learning approach on instructional multimedia development courses in teacher education. Interactive $\begin{array}{llll}\text { Learning } & \text { Environments, } & 22 & \text { (4), }\end{array}$ https://doi.org/10.1080/10494820.2012.682586

11. The definition of blended learning Teachthought. We grow teachers. [Internet resource]: https://www.teachthought.com/learning/the-definition-of-blended-learning. Date of request: 23.09.2020 (2020).

12. Cakir, H., Bichelmeyer, B.A. Effects of teacher professional characteristics on student achievement: An investigation in blended learning environment with standards-based curriculum. Interactive Learning Environments, 24 (1), 20-32. (2016) https://doi.org/10.1080/10494820.2013.817437

13. Berenson, R., Boyles, G., Weaver, A. (2008). Emotional intelligence as a predictor for success in online learning. International Review of Research in open \& Distance Learning, 9 (2), 1-16

14. Adams Becker, S., Cummins, M., Davis, A., Freeman, A., Hall Giesinger, C., Ananthanarayanan, V. NMC horizon report: 2017 higher Education Edition. Austin: The New Media Consortium. (2017)

15. Bernard, R.M., Borokhovski, E., Schmid, R.F., Tamim, R.M., Abrami, P.C. (A metaanalysis of blended learning and technology use in higher education: From the general to the applied. Journal of Computing in Higher Education, 26 (1), 87-122. (2014). https://doi.org/10.1007/s12528-013-9077-3

16. Daun, M., Tenbergen, B., Salmon, A., Weyer, T., Pohl, K. Project-based Learning with Examples from Industry in University Courses 59-60, (2017)

17. Cohen, K.E., Stage, F.K., Hammack, F.M., Marcus, A. Persistence of master's students in the United States: Developing and testing of a conceptual model. USA: PhD Dissertation, New York University (2012)

18. Moskal, P., Dziuban, C., Hartman, J. Blended learning: A dangerous idea? The Internet and Higher Education, 18, 15-23 (2013)

19. Allen, I.E., Seaman, J., Poulin, R., Straut, T.T. Online report card: Tracking online education in the United States, 1-4. (2016). Retrieved from http://onlinelearningsurvey.com/reports/onlinereportcard.pdf

20. Floridi, L. The 4th revolution: How the infosphere is reshaping human reality (Oxford: Oxford University Press, 2014)

21. Bloemer, W., Swan, K. Investigating informal blending at the University of Illinois Springfield. In A.G. Picciano, C.D. Dziuban, \& C.R. Graham (Eds.), Blended learning: Research perspectives, 2, 52-69 (New York: Routledge, 2015)

22. Hrastinski, S. What Do We Mean by Blended Learning? TechTrends, 63: 564-569 (2019) https://doi.org/10.1007/s11528-019-00375-5 
23. Dziuban, C.D., Hartman, J.L., Moskal, P.D. Blended learning. EDUCAUSE Research Bulletin, 7, 1-12 (2004) 